Supplement of Biogeosciences, 16, 4097-4111, 2019

https://doi.org/10.5194/bg-16-4097-2019-supplement

(C) Author(s) 2019. This work is distributed under

the Creative Commons Attribution 4.0 License.

(c) (i)

Supplement of

\title{
A multi-year observation of nitrous oxide at the Boknis Eck Time Series Station in the Eckernförde Bay (southwestern Baltic Sea)
}

Xiao Ma et al.

Correspondence to: Xiao Ma (mxiao@geomar.de)

The copyright of individual parts of the supplement might differ from the CC BY 4.0 License. 


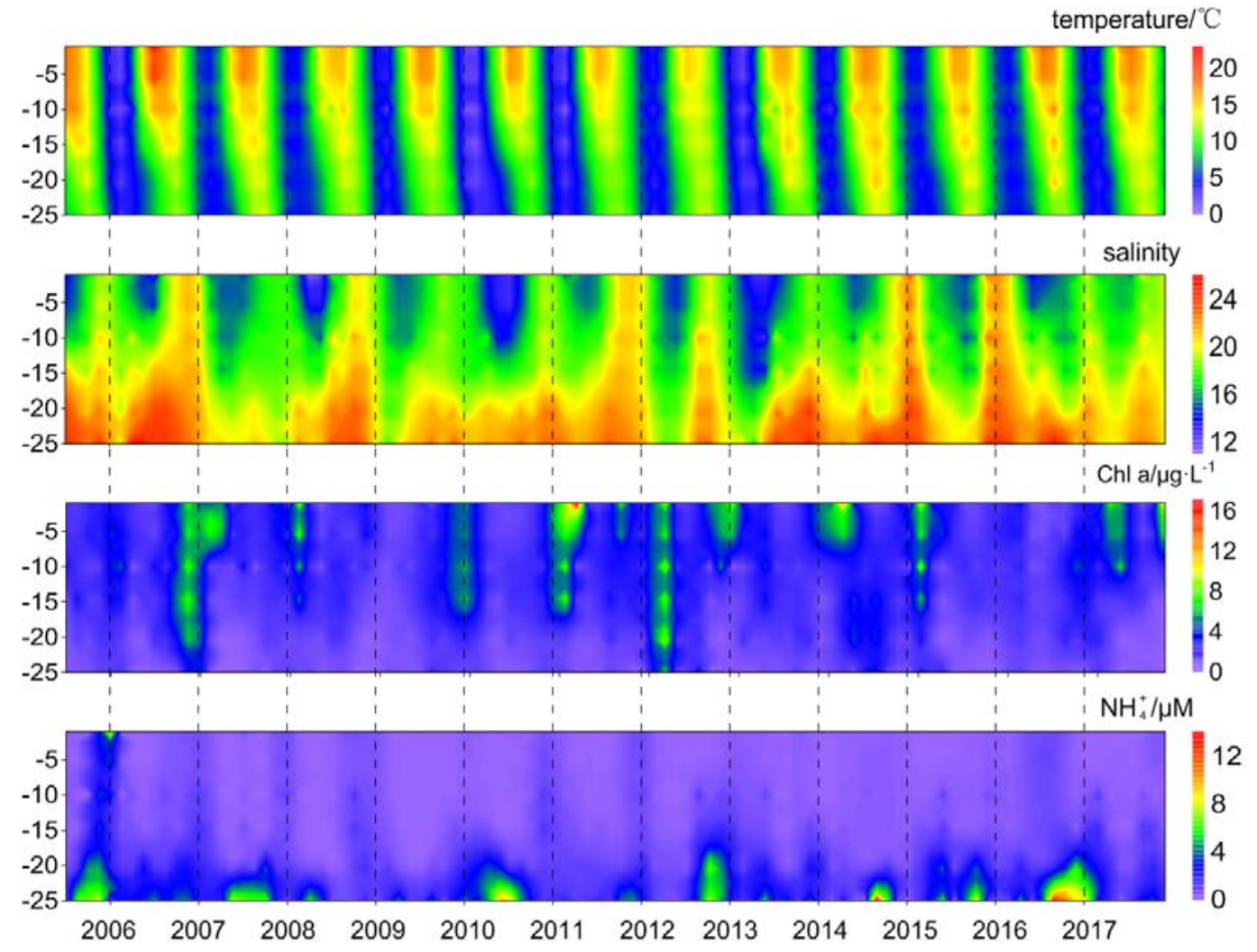

Supplementary Figure 1. Vertical distributions of temperature, salinity, chlorophyll $a$ and $\mathrm{NH}_{4}{ }^{+}$ from the BE Time-Series Station during 2005-2017. Please note that high $\mathrm{NH}_{4}{ }^{+}$concentrations ( $>20 \mu \mathrm{M} / \mathrm{L}$, which are detected in the bottom water of October 2005, May 2006, October 2013, October 2014, October and November 2016) were removed for better visualization. 


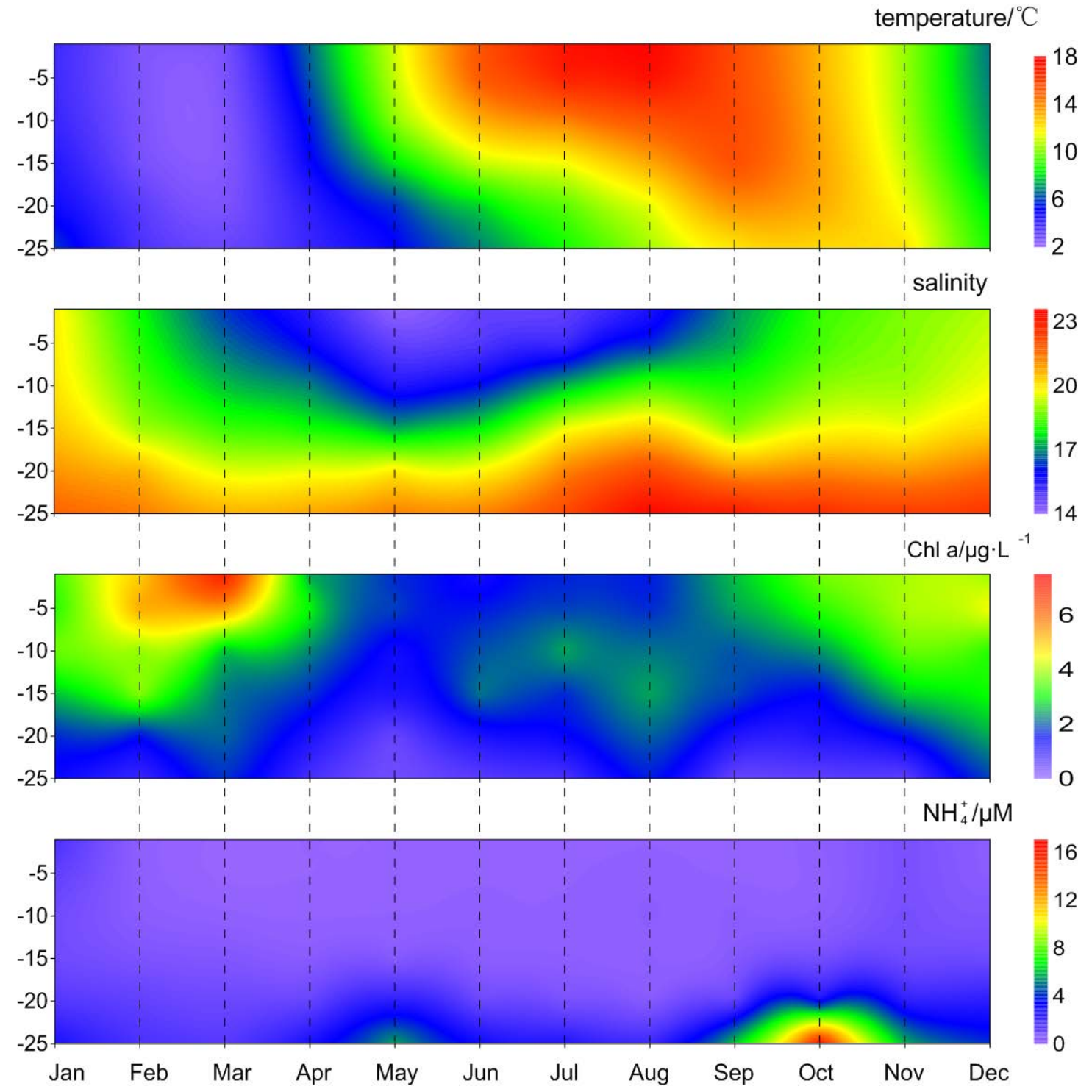

Supplementary Figure 2. Average vertical distributions of temperature, salinity, chlorophyll $a$ and $\mathrm{NH}_{4}{ }^{+}$from the BE Time-Series Station during 2005-2017 